\title{
PLURALIDAD DE ELEMENTOS QUE INTEGRAN EL DERECHO *
}

A través de las páginas precedentes nos hemos aproximado al "objeto" del Derecho y se le ha mostrado como un objeto cultural.

El objeto del Derecho es conducta humana en su interferencia intersubjetiva. En tanto que conducta es libertad metafísica que se exterioriza, que aparece en el murido fenoménico. Libertad en su dimensión de coexistencia. El Derecho es, ontológicamente, libertad fenomenalizada.

Por ser libertad fenomenalizada, en su interferencia intersubjetiva, la conducta tiene una estructura estimativa, desde que todo elegir supone un preferir y todo preferir es un valorar. La conducta es la realidad que realiza valores, que encarna valores. Es sustrato o soporte de aquéllos.

* El presente texto es la primera parte del capítulo IV del trabajo inédito intitulado Bosquejo para una determinación ontológica del Derecho (Lima 1950, pp. 169-177) que fue presentado por el doctor Carlos Fernández Sessarego, como tesis para el Bachillerato en la Facultad de Derecho de San Marcos. En dicha tesis, obra de extrema juventud $y$ en donde no obstante se of rece un meditado y valioso enfocue introductorio a la filosofía del derecho, su autor, fuertemente influenciado por las concepciones de la época (la teoría egológica de Carlos Cossio en la filosofía jurídica y el existencialismo en la filosofía general) plantea desde un ángulo novedoso y original la presencia de tres elementos como integrantes indisolubles del Derecho, que sólo años más tarde y merced a la obra de Miguel Reale (Filosofía do Direito, São Paulo, 1953) adquiriría dimensión internacional con el nombre de teoría tridimensional del Derecho. El anticipo de esta teoría no sólo amerita la labor de su autor sino la presencia de nuestro país en la meditación jusfilosófica. Una breve referencia sobre este trabajo puede hallarse en La filosofía del Derecho en el Perú de Mario Alzamora Valdez; Lima 1968, pp. 121-124 (Domingo Carcía Belaunde).
Desde un punto de vista estimativo la conducta humana en su dimensión de coexistencia, en su interferencia intersubjetiva, realiza valores éticos; y, entre éstos, los llamados valores comunitarios o jurídicos.

Esta conducta, en su interferencia intersubjetiva, realizando ciertos valores, es caracterizada formalmente por el pensamiento normativo. La conducta humana como deber ser existencial es pensada, representada, en su libertad estimativa a través de una estructura de pensamiento distinto de aquel con que se enuncia al ser estático: se le piensa con una lógica del deber ser. La norma jurídica es un juicio imputativo de deber ser de carácter disyuntivo que, en uno de sus miembros, comporta una sanción.

Las normas, como juicios disyuntivos, piensan a la conducta como valiosa o desvaliosa. Un miembro del juicio disyuntivo - la endonorma- piensa a la conducta como facultad, es decir como libertad jurídica $y$, el otro - la perinorma-, como entuerto al que corresponde una sanción.

La facultad jurídica, como lo ha mostrado Carlos Cossío, es susceptible de una especificación: como facultad de señorío en cuanto su contenido es autónomo, no determinado por la norma, y como facultad de inordinación en cuanto su contenido es determinado heterónomamente por la norma.

La norma -en cuanto objeto lógico-, al representar a la conducta humana, la mienta encarnando valores. Las normas, como tales, son neutras al valor. Sólo se refieren a él al mentar su objeto conducta, la que, como está dicho, es ontológicamente valorativa.

La realidad jurídica es compleja. Existe una pluralidad de elementos que integran la ciencia juridica. Y para captar adecuadamente lo "jurídico" se requiere no prescindir de ninguno de ellos. Los estratos ontológico, estimativo y lógico se exigen mutuamente 
en una unidad. En la unidad del Derecho. Podemos apreciar aisladamente la conducta como libertad, las normas como pensamiento y los valores como ideales objetivos con validez propia pero, para captar lo "jurídico" en su integridad, debemos considerar aquellas categorias en su inescindible unidad.

No hay Derecho sin conducta humana en su interferencia intersubjetiva, sin valores inmanentes a ella - sin dejar por esto de ser objetivos-, sin normas que representen a la conducta estimativa y que comportan una coacción. Podemos desplegar aquellos elementos y hacerlos tema, respectivamente, de la Ontologia, la Estimativa y la Lógica juridicas. Mas, si queremos apreciar el Derecho, "lo jurídico", tenemos que considerarlos en su inescindible unidad, en su mutua exigencia.

Como afirma Ramón M. Alsina "Ia demostración de esta pluralidad de elementos que integran el derecho como objeto cultural, no destruye en modo alguno la unidad de su Ser, antes bien la confirma, ya que tales elementos se exigen mutuamente formando una síntesis inescindible"' (1). No existe Derecho sin conducta humana en su interferencia intersubjetiva, ni valoración sin conducta, ni conducta sin valoración, ni conducta estimativa sin una estructura lógica-gnoseológica de pensamiento que la manifieste y sirva para interpretarla.

Conducta, valor y norma. Tres categorias que en su mutua exigencla conforman "lo jurídico". Ontologia, Estimativa y Lógica jurídicas, como temas de la filosofía del Derecho, haciéndose cargo de cada una de aquellas categorías, respectivamente. Del Derecho como objeto a conocer, como libertad fenomenalizada en su interferencia intersubjetiva, se ocupa la Ontología. El Derecho, como plexo de valores que se encarnan en su objeto específico -que es la conducta humana social- determinando cuáles, sean, especificando su jerarquía y sus conexiones, su cumplimiento o incumplimiento-, es tema de la Estimativa jurídica. Del Derecho como norma, como pensamiento que se refiere a un objeto que es vida humana vivienie, del estudio de la estructura lógica-gnoseológica del pensamiento jurídico, se ocupa la Lógica jurídica. Más, y en esto aceptamos el punto de

1. ALSINA RAMON, M., Introducción a la problemática jurídica actual en Curso Colectivo de filosofía del Derecho; Bs. Aires 1943, p. 13. vista de Cossio, la Lógica juridica comprende dos capítulos: la Lógica jurídica formal, que estudia la estructura del pensamiento juridico, del pensamiento como pensamiento en mínima referencia a su objeto, y la Lógica jurídica trascendental que se ocupa del pensamiento jurídico ya no en su estructura formal sino con una máxima referencia a su objeto, como conocimiento, rastreándolo. Como dice el mismo autor, en la Lógica formal el pensamienio está apoyado al mínimo en el objeto y "se retrovierte sobre sí mismo para estudiarse en su estructura". En la Lógica trascendental "el pensamiento se investiga apoyado al máximo en su objeto", está guiado por su objeto y la investigación "recae en primer término sobre todos los actos gnoseológicos de aprehensión que realiza el pensamiento" (2). Y esta Lógica trascendental "supone y lleva encerrada una ubicación ontológica de la realidad jurídica" (3). La Lógica se apoya en la Ontología.

Al especificar los temas de la filosofía de la ciencia jurídica debemos distinguir con claridad los planos lógico, ontológico y estimativo, planos que, con frecuencia, se les confunde. En la Ontología jurídica lo dado son las acciones humanas, en cuanto libertad actuante, y su tema es la descripción esencial de la experiencia jurídica. En la Estimativa lo dado son los valores como objetividades en la vida humana, debiendo ella determinar cuáles son los valores jurídicos, establecer su jerarquía y conexiones, su cumplimiento e incumplimiento. En la Lógica juridica lo dado es el pensamiento normativo, ya sea como pensamiento en si -en su estructura formal- o como conocimiento aproximándose al máximo al objeto mentado. En el primer caso iendremos la Lógica formal $y$, en el segundo, la Lógica trascendental.

Tanto la Axiología o Estimativa como la Lógica jurídicas reposan en la Ontologia, desde que los problemas estimativo y lógico se elaboran sobre el objeto especifico del Derecho. En la Ontología cobra unidad la filosofía del Derecho.

Los valores jurídicos, al ser en cierta forma inmanentes a la conducta - desde que ella es su soporte $y$ en ella adquieren realidad ya que la vida humana

2. COSSIO Carlos, La Teoría Egológica del Derecho, Bs. Aires, 1944, p. 195.

3. NIETO ARTETA, Lógica, fenomenología y formaIismo jurídico, Santa $\mathrm{Fe}$, 1942, p. 39. 
es su ámbito y forman parte de su peculiar contextura, lo que hace que la conducta sea ontológicamente valorativa - se encuentran siempre referidos a la vida humana viviente, haciendo de ella un objeto cultural. Por eso, toda elaboración de carácter estimativo es desarrollo ulterior del planteamiento ontológico que nos muestra el objeto del Derecho como libertad actuante. El problema estimativo se elabora sobre la Ontología.

Si no cabe ontológicamente conducta sin valor, descle que éste pertenece a la contextura de aquella, Ontología y Estimativa se exigen mutuamente, conducta $y$ valor se exigen mutuamente. Aunque es cierto que, para comprender claramente el problema estimativo del Derecho, se hace previa la tarea de mostrar, de elucidar, el problema ontológico de la libertad como conducta en su dimensión de co-existencia.

Todo pensamiento es pensamiento de algo; no cabe ontológicamente pensamiento sin objeto (4). Toda norma, como juicio disyuntivo, se refiere a una conducta, es pensamiento de una conducta en su interferencia intersubjetiva. La lógica jurídica, como está dicho, se hace cargo de la conceptuación de la conducta en tanto pensamiento y en tanto conocimiento y se apoya, asimismo, en el objeto mentado o conocido que es la conducta humana social. El objeto determina la clase de juicios con que debe ser pensado. Asi, al "ser" corresponde el juicio entitativo o enunciativo y al "deber ser" existencial -a la libertad estimativa- le acomoda el juicio imputativo de deber ser. En cierta forma el pensamiento es también inmarente al objeto pensado. La Lógica juridica, por tanto, se apoya en la Ontología al seguir el pensamiento a su objeto pensado.

Es asi como la Lógica jurídica, que tradicionalmente se consideraba como Lógica del ser, fue desplazada por la Lógica del deber ser cuando el genial Hans Kelsen intuyó que el objeto del Derecho -aunque imprecisamente- era la conducta humana, un "fenómeno social" (5). El que Kelsen vislumbrara que la conducta humana era el contenido de la norma jurídica determinó que el pensamiento de este singular objeto conducta -que Kelsen no trató filosóficamente y del que tenia, como está dicho, una noción impre-

4. PFANDER, Lógica, Bs. Aires, 1945 pp. 13, 45.

5. KELSEN HANS, La Teoría Pura del Derecho, Bs. Aires, 1946, p. 26. cisa-, originalmente situado en la Lógica del ser, fuera tratado por la Lógica del deber ser.

La vinculación entre la norma y el valor se produce por constituir la primera la representación de la conducta humana social, la que es en sí justa o injusta, que es en sí cierta seguridad o cierio orden. Ella se produce por ser la norma la representación de una conducta valiosa o desvaliosa, de una conducta realizando valores. El valor no es trascendente a la norma en el sentido que él sea una "estrella polar" que la oriente, que la guie. El valor se relaciona con la norma a través de la conducta que lo realiza y que es pensada por la norma en este su carácter estimativo. La Lógica no se fundamenta en la Axiología -como es la opinión de cierto sector del pensamiento jusfilosófico- sino en la Ontología jurídica.

Es asi como se despliegan los elementos que conforman el Derecho; elementos que se exigen mutuamente sin confundirse y que cobran unidad en el "objeto" Derecho. Conducta, norma y valor son los elementos ontológico, lógico y estimativo del Derecho que en unidad integral motivan su aparición. $Y$ el Derecho no es ninguno de estos elementos en forma aislada. El Derecho no es conducta; el Derecho no es valor; el Derecho no es norma. El Derecho es la integración de aquellos elementos: es conducta humana en su interferencia intersubjetiva, realizando o dejando de realizar valores juridicos, representada a través de normas que son juicios imputativos de deber ser de carácter disyuntivo.

Nota del Autor (1973). La benevolencia de los miembros del Consejo Editorial de la Revista "Derecho" hace posible la publicación de algunos breves párrafos de un trabajo presentado como tesis de Bachiller, en 1950. Escrita entre los años de 1946-1949, ella representa - como se anota en el Prólogo- una inquietud "nacida en los umbrales del aprendizaje del Derecho en los claustros de San Marcos". Inquietud por desentrañar el profundo sentido del Derecho en la vida del hombre, por intentar una respuesta, aunque provisional, "a la vieja y siempre nueva interrogante por el ser del Derecho que ... nos proporcione una visión unitaria de la disciplina a la que ofrendamos cotidianamente nuestros más caros y preciados esfuerzos".

Al repasar el texto, con la perspectiva de casi veinticinco años, reencontramos, fresca y espontánea, una antigua y terca vocación por poner el Derecho al ser- 
vicio del hombre, como instrumento de liberación. Por contrarrestar toda construcción teórico-ideológica que desfigure y utilice al Derecho como mero "sistema normativo de dominación de unos hombres sobre otros". Tal vez por ello se expresa, también en el Prólogo, la pretensión de que el trabajo de juventud sea "parte de inquietudes del hombre actual, vivencias jurídicas desde la perspectiva histórica de nuestra época, tarea irrenunciable de una generación que vive auténticamente tiempo presente".

Las páginas que se transcriben trasuntan un esbozo de solución contraria a todo unidimensionalismo jusfilosófico. La posición que se adopta, a través de todo el trabajo, supone una crítica al planteamiento kelseniano - vigente en la época- de reducir el Derecho a una pura normatividad, asi como es contraria a todas aquellas sustentaciones del Derecho Natural y a las más diversas formas de sociologismos o historicismos jurídicos. Tomando como base una fenomenología existencial y la teoría egológica, se muestra al Derecho en una triplicidad de elementos "que se exigen mutuamente", que se integran en la unidad del objeto Derecho. Es así que aparece la conducta jurídica con su tridimensionalidad. La obra tiende a presentar el Derecho inserto en la dimensión coexistencial de la vida humana. Por ello, se rechaza todo intento normativista por deshumanizarlo, por convertirlo en mera construcción. Sólo un plantea- miento personalista del Derecho, al intuirlo en su unidad ontológica, permite situarlo como la tarea inacabada del hombre por conquistar la vivencia comunitaria de justicia, como solidaridad, seguridad, paz y cooperación, al servicio de su libertad radical. Sólo así es posible concebirlo como factor dinámico de la transformación y el cambio social y no como un conjunto de normas que congelan el statu quo imperante.

En el Perú de aquel entonces - década del cuarenta - gravitaba fundamentalmente la escuela del Derecho Natural en su versión neo-tomista, el normativismo de Kelsen y Schrier, el pensamiento de Radbruch, Stammler y Del Vecchio. Acababan de llegar las valiosas obras de Recanséns Siches y Cossio.

No se conocía la hoy tan difundida teoría tridimensional de Reale ni el perspectivismo de García Máynez, ni se habían publicado los importantísimos trabajos de Klug, Miró Quesada, Von Wright, Alf Ross, Hart, Jerome Hall y Neri Castañeda.

No es esta breve nota ocasión propicia para contrastar nuestro pensamiento actual con el de hace veinticinco años ni para destacar los errores ínsitos en las páginas que se publican, las que, por lo demás, mantienen su redacción original. Pero sí, podemos declarar $\mathrm{s}$ e conservamos enhiesta la misma inquietud y vocación de aquel entonces, el mismo "pertinaz afán por encontrar una respuesta a la vieja y siempre nueva interrogante por el ser del Derecho ..." 